\title{
Effects of size and surface of zinc oxide and aluminum-doped zinc oxide nanoparticles on cell viability inferred by proteomic analyses
}

This article was published in the following Dove Press journal:

International Journal of Nanomedicine

2 August 2014

Number of times this article has been viewed

\author{
Chih-Hong Pan ${ }^{1,2, *}$ \\ Wen-Te Liu ${ }^{3,4, *}$ \\ Mauo-Ying Bien ${ }^{4,5}$ \\ I-Chan Lin ${ }^{6}$ \\ Ta-Chih $\mathrm{Hsiao}^{7}$ \\ Chih-Ming $\mathrm{Ma}^{8}$ \\ Ching-Huang Lai ${ }^{2}$ \\ Mei-Chieh Chen ${ }^{9}$ \\ Kai-Jen Chuang ${ }^{10,11}$ \\ Hsiao-Chi Chuang ${ }^{3,4}$ \\ On behalf of the Taiwan \\ CardioPulmonary Research \\ (T-CPR) Group
}

'Institute of Labor, Occupational Safety and Health, Ministry of Labor,

${ }^{2}$ School of Public Health, National

Defense Medical Center, ${ }^{3}$ Division of

Pulmonary Medicine, Department of

Internal Medicine, Shuang Ho Hospital,

${ }^{4}$ School of Respiratory Therapy,

College of Medicine, ${ }^{5}$ Division of

Pulmonary Medicine, Department

of Internal Medicine, Taipei Medical

University Hospital, ${ }^{6}$ Department of

Ophthalmology, Shuang Ho Hospital,

Taipei Medical University, Taipei,

${ }^{7}$ Graduate Institute of Environmental

Engineering, National Central

University, Taoyuan, ${ }^{8}$ Department

of Cosmetic Application and

Management, St Mary's Junior College

of Medicine, Nursing and Management,

Sanxing, ${ }^{9}$ Department of Microbiology

and Immunology, College of Medicine,

${ }^{10}$ Department of Public Health, School

of Medicine, College of Medicine,

"School of Public Health, College of

Public Health and Nutrition, Taipei

Medical University, Taipei, Taiwan

*These authors contributed equally to this work

Correspondence: Hsiao-Chi Chuang/KaiJen Chuang

School of Respiratory Therapy/

Department of Public Health, School of

Medicine, College of Medicine, Taipei

Medical University, 250 Wuxing Street,

Taipei, Taiwan 110

Tel +886 22736 I66I ext 35I5/6536

Fax +88622739 I| 43/2738-483।

Email r92841005@ntu.edu.tw:

kjc@tmu.edu.tw
Abstract: Although the health effects of zinc oxide nanoparticles (ZnONPs) on the respiratory system have been reported, the fate, potential toxicity, and mechanisms in biological cells of these particles, as related to particle size and surface characteristics, have not been well elucidated. To determine the physicochemical properties of ZnONPs that govern cytotoxicity, we investigated the effects of size, electronic properties, zinc concentration, and $\mathrm{pH}$ on cell viability using human alveolar-basal epithelial A549 cells as a model. We observed that a 2-hour or longer exposure to $\mathrm{ZnONPs}$ induced changes in cell viability. The alteration in cell viability was associated with the zeta potentials and $\mathrm{pH}$ values of the $\mathrm{ZnONPs}$. Proteomic profiling of A549 exposed to ZnONPs for 2 and 4 hours was used to determine the biological mechanisms of ZnONP toxicity. p53-pathway activation was the core mechanism regulating cell viability in response to particle size. Activation of the Wnt and TGF $\beta$ signaling pathways was also important in the cellular response to ZnONPs of different sizes. The cadherin and Wnt signaling pathways were important cellular mechanisms triggered by surface differences. These results suggested that the size and surface characteristics of ZnONPs might play an important role in their observed cytotoxicity. This approach facilitates the design of more comprehensive systems for the evaluation of nanoparticles.

Keywords: aluminium-doped zinc oxide, nanoparticle, $\mathrm{pH}$, toxicology, WNT pathway, zeta potential

\section{Introduction}

Nanoparticles (NPs) are used in various commercial products and for novel applications in sunscreens, engineering, and biomedicine. However, the fate, potential toxicity, and cellular mechanisms of these particles are not well understood. Human contact with NPs is increasing, and regulatory guidelines are not presently available. Therefore, the development of reliable high-throughput in vitro test systems for use in product design and for cytotoxicity evaluations would be advantageous for assessing efficiency and for the extrapolation of NP effects to humans. Previous in vitro observations have been based on known toxicity mechanisms; ${ }^{1,2}$ however, it is unclear whether these experiments provide sufficient toxicological information for comprehensive assessment of the potential toxicity of NPs.

Zinc oxide NPs (ZnONPs) are produced for many applications, such as antimicrobials $^{3}$ and cancer therapy. ${ }^{4}$ For example, specifically designed ZnONPs can enhance the ability of NPs to target specific types of cancer cells, pass through physiological barriers, and interact with tumor sites. ${ }^{4}$ An increasing number of studies propose that the common pathogenic mechanisms of ZnONPs, such as cell death, are related to oxidative stress imbalances. ${ }^{5,6}$ Previous studies have shown that ZnONPs are more toxic than macrosized fractions. ${ }^{7}$ The electrostatic nature of NPs is also an important characteristic, 
as electrostatic interactions between charged NPs and target cells likely play an important role in the regulation of particle uptake by cells. ${ }^{8,9}$ Doping ZnONPs with metals, such as aluminum (Al-ZnONPs), can specifically enhance the NPs' electrical and optical properties. ${ }^{10}$ Because transition metals can regulate redox-cycling cascades, transition metal-doped ZnONPs have the potential to improve therapeutic techniques. ${ }^{11}$ Certain studies suggest that the toxicity of ZnONPs may be due to the zinc ion; ${ }^{12,13}$ however, others indicate that a significant association between $\mathrm{ZnONPs}$ and zinc ion toxicity does not exist. ${ }^{14}$ In addition, previous studies have shown that intracellular $\mathrm{pH}$ increases during cell-cycle progression and proliferation. ${ }^{15,16}$ Therefore, the alteration in $\mathrm{pH}$ could be associated with electrostatic interactions with charged particles at the cell membrane. ${ }^{17}$ Given these hypothesized mechanisms, tailoring the size and surface characteristics of $\mathrm{ZnONPs}$ is expected to influence their cytotoxicity, and these will likely be important characteristics to consider when developing cancer therapies.

High-throughput approaches, such as toxicoproteomics, which includes proteomics and metabonomics, have the potential to provide an unbiased evaluation of the biological response of an organism or a cell to adverse stressors. ${ }^{18}$ Therefore, the use of such a platform as proteomics can determine all relevant toxicity pathways when combined with bioinformative techniques. ${ }^{19}$ Biomarkers in biological fluids, such as cell supernatants, ${ }^{20}$ bronchoalveolar lavage fluids, ${ }^{19}$ and blood samples, ${ }^{21}$ can be measured for several purposes. Okoturo-Evans et al investigated the toxicological mechanism of silicon dioxide NPs in lung cells, ${ }^{2}$ and suggested that proteomic approaches would facilitate the design of a more focused test system for the evaluation of NP toxicity.

$\mathrm{ZnO}$ is generally recognized as a safe material by the US Food and Drug Administration, but this designation most commonly refers to materials larger than nanoscale fractions. As a result, a comprehensive evaluation of $\mathrm{ZnONP}$ toxicity is required, as well as an assessment of particle effects on human health. In this study, we explored the feasibility of using proteomics to investigate changes in the viability of NP-exposed human alveolar basal epithelial A549 cells as a basis for the development of high-throughput screens and for the more focused assessment of differences in the size and surface characteristics of ZnONPs. Finally, based on the identified proteins, we analyzed the biological processes involved in $\mathrm{ZnONP}$-induced cell death.

\section{Materials and methods ZnONPs and reagent sources}

The sources and physical properties of the ZnONPs and Al-ZnONPs used in this study are listed in Table 1. All of the other reagents were obtained from Sigma-Aldrich (St Louis, MO, USA), unless the source is explicitly stated.

\section{Field-emission scanning electron microscopy and energy-dispersive $X$-ray microanalysis}

To investigate the physicochemical changes in ZnONPs and Al-ZnONPs pre- and postsuspension in $\mathrm{dH}_{2} \mathrm{O}$ or $10 \%$ fetal bovine serum (FBS), field-emission scanning electron microscopy (FE-SEM; Inspect ${ }^{\mathrm{TM}}$ 2100; JEOL, Tokyo, Japan) and energy-dispersive X-ray (EDX) microanalysis were used in this study. Samples were vortexed and sonicated for $10 \mathrm{~min}$ utes and then lyophilized for the FE-SEM and EDX analyses. The preparation protocols for the FE-SEM and EDX analyses have been previously reported. ${ }^{22}$ The samples were adhered onto $12 \mathrm{~mm}$ carbon sticky tabs, which were fixed on $13 \mathrm{~mm}$ aluminum SEM stubs. The samples were coated with platinum to an average thickness of $10 \mathrm{~nm}$ using a sputter coater and then imaged. FE-SEM was operated at an accelerating voltage of $15 \mathrm{kV}$ using a 2.5 spot size. Elemental analysis was performed using the EDX Genesis microanalysis system.

\section{Physicochemical characterization of ZnONPs in FBS-containing medium}

$\mathrm{ZnONP}$ solutions were freshly prepared at 20, 50, 150, 300 , or $500 \mu \mathrm{g} / \mathrm{mL}$ in $10 \%$ FBS-containing cell medium by vortexing for $0,0.5,1,6,12,24$, and 48 hours at room temperature. The hydrodynamic diameters of the particles were determined using dynamic light scattering (Zetasizer Nano ZS; Malvern Instruments, Malvern, UK). The zeta potentials

Table I Sources and physical characteristics of the zinc oxide nanoparticles (ZnONPs). Unless otherwise stated, the data are based on information that was provided by the supplier

\begin{tabular}{lllll}
\hline & Company & Average diameter & Purity $(\mathbf{w t} \%)$ & Specific surface area $\left(\mathbf{m}^{2} / \mathbf{g}\right)$ \\
\hline ZnONP20 & Nanostructured and Amorphous Materials & $20 \mathrm{~nm}$ & 99.5 & 50 \\
ZnONP90 & Nanostructured and Amorphous Materials & $90-210 \mathrm{~nm}$ & 99.9 & $4.9-6.8$ \\
Al-ZnONP20 & Nanostructured and Amorphous Materials & $20-40 \mathrm{~nm}$ & $\mathrm{ZnO}_{\mathrm{Al}} \mathrm{O}_{3}=98: 2$ & $\mathrm{NA}$ \\
\hline
\end{tabular}

Abbreviation: NA, not available. 
of the samples were also determined using the Zetasizer Nano ZS. Changes in the solution $\mathrm{pH}$ levels were determined using a $\mathrm{pH}$ meter. To determine zinc concentrations, the samples were centrifuged at $1,000 \mathrm{rpm}(500 \mathrm{~g})$ for 10 minutes and then filtered using a $0.45 \mu \mathrm{m}$ polyvinylidene difluoride filter (Chrom Tech, Apple Valley, MN, USA). ${ }^{23}$ A flame atomic absorption spectrophotometer (AAnalyst ${ }^{\mathrm{TM}} 800$; PerkinElmer, Waltham, MA, USA) was used to determine the concentrations of zinc ions leached from the ZnONPs.

\section{Cell culture and treatment}

Human alveolar basal epithelial A549 cells were obtained from the American Type Culture Collection (Manassas, VA, USA) and cultured in Roswell Park Memorial Institute (RPMI) medium containing 10\% FBS, penicillin, and streptomycin. There was no endotoxin detected in the ZnONPs or Al-ZnONPs (Pierce LAL chromogenic endotoxin quantitation kit; Thermo Fisher Scientific, Waltham, MA, USA). To investigate NP-induced changes in cell viability, A549 cells were incubated with $0,20,50,150,300$, and $500 \mu \mathrm{g} / \mathrm{mL} \mathrm{ZnONPs}$ or $\mathrm{Al}-\mathrm{ZnONPs}$ at $37^{\circ} \mathrm{C}$ for $0-48$ hours in a humidified atmosphere containing $5 \% \mathrm{CO}_{2}$. The $\mathrm{ZnONPs}$ and $\mathrm{Al}-\mathrm{ZnONPs}$ were not washed before the cell treatments. Each experiment was conducted in quadruplicate.

\section{Real-time monitoring of cell viability using the $\times C E L L i g e n c e$ system}

To investigate the real-time viability of A549 cells after exposure to ZnONPs or Al-ZnONPs, the xCELLigence system (Hoffman-La Roche, Basel, Switzerland) was used. The principle of the system has been reported previously. ${ }^{24}$ Briefly, the xCELLigence system monitors cellular events in real time by recording the electrical impedance that correlates with the cell number, morphology, and viability in a given culture well of an E-plate. The concentration of A549 cells was adjusted to 100,000 cells per $200 \mu \mathrm{L}$ and loaded into the wells of microtiter E-plates ( 96 wells) after obtaining the background impedance of the plates. The cell background impedance was monitored every 5 minutes for the first 20 hours. The RPMI medium was removed before adding $200 \mu \mathrm{L}$ of each $\mathrm{ZnONP}$ or Al-ZnONP sample, prepared in media at particle concentrations of 0 , $20,50,150,300$, and $500 \mu \mathrm{g} / \mathrm{mL}$. For the next 48 hours, cell impedance was monitored, and the electrical impedance was calculated using the RTCA-integrated software of the xCELLigence system. The electrical impedance was expressed as a dimensionless parameter, termed the cell index (cell-viability index).

\section{Characterization of proteomic profiling}

To investigate global protein expression in A549 cells after exposure to $20 \mu \mathrm{g} / \mathrm{mL} \mathrm{ZnONPs}$ or Al-ZnONPs, supernatant fractions were collected after 2 and 4 hours of exposure. The preparation of samples for proteomic analyses has been reported previously. ${ }^{19}$ Briefly, the supernatants were diluted with $50 \mathrm{mM}$ ammonium bicarbonate. The samples were denatured and reduced with $8 \mathrm{M}$ urea/ $10 \mathrm{mM}$ dithiothreitol and alkylated with $50 \mathrm{mM}$ iodoacetamide. The samples were then digested with trypsin in $25 \mathrm{mM}$ ammonium bicarbonate and desalted by $\mathrm{C} 18$ columns. The tryptic peptides were then analyzed using a Q Exactive ${ }^{\mathrm{TM}}$ mass spectrometer (Thermo Fisher Scientific) coupled with an Dionex UltiMate ${ }^{\circledR} 3000$ RSLC system (Thermo Fisher Scientific). The peptides were separated by liquid chromatography using C18 columns $\left(75 \times 150 \mathrm{~mm}, 2 \mu \mathrm{m}\right.$, Dionex Acclaim ${ }^{\circledR}$ PepMap $^{\mathrm{TM}}$ RSLC; Thermo Fisher Scientific). The separation conditions have been described previously. ${ }^{19}$ Full mass spectrometry (MS) scans were performed using ranges of $\mathrm{m} / \mathrm{z} 380-2,000, \mathrm{~m} / \mathrm{z}$ $380-600, \mathrm{~m} / \mathrm{z} 600-800, \mathrm{~m} / \mathrm{z} 800-1,200$, and $\mathrm{m} / \mathrm{z}$ 1,200-2,000, and the ten most intense ions from the MS scans were selected for MS/MS scans. The raw data were processed into peak lists using Proteome Discoverer 1.3 for Mascot database searching (Matrix Science, London, UK) and National Center for Biotechnology Information UniProt database prediction and literature searching. The search parameters included variable modifications for deamidation (NQ), oxidation (M), and a fixed modification for carbamidomethyl $(\mathrm{C})$. The maximum mass tolerance was set to $10 \mathrm{ppm}$ for precursor ions and to $0.05 \mathrm{Da}$ for fragment ions.

\section{Protein functional analyses}

The expressed proteins were subjected to functional pathway analyses using the PANTHER (Protein ANalysis THrough Evolutionary Relationships) classification system (http:// www.pantherdb.org) to determine the biological context of the identified proteins. ${ }^{25}$ The UniProt accession database was used to access the expressed proteins identified in this study. The identified proteins were uploaded and mapped against the Homo sapiens reference data set to extract and summarize the functional annotations associated with individual proteins or groups of proteins and to identify the biological processes, molecular functions, and pathways for each data set.

\section{Data analysis}

Statistical analyses were performed using GraphPad version 5 for Windows (GraphPad Software, La Jolla, CA, USA). Student's $t$-test was used for comparisons of the data 
between groups. Pearson's correlation coefficient was used to examine the correlation of time-dependent cell viability with time-dependent physicochemical alterations. The level of significance was set at $P<0.05$.

\section{Results}

\section{Physicochemical characterization}

ZnONPs, including ZnONP20 (average diameter of $20 \mathrm{~nm}$ ), ZnONP90 (average diameter of 90-210 nm), and Al-ZnONP20 (average diameter of 20-40 nm), were used to investigate the effects of the size and surface characteristics of $\mathrm{ZnONPs}$ on a biological system. The supplier provided the basic characteristics of the ZnONPs (Table 1). Morphological and elemental changes in the ZnONPs pre- and postsuspension in $\mathrm{dH}_{2} \mathrm{O}$ and $10 \%$ FBS-containing medium (Figure 1) were examined first. We found that ZnONP20, ZnONP90, and Al-ZnONP20 were regular in shape, and significant morphological change did not occur when the ZnONPs were suspended in $\mathrm{dH}_{2} \mathrm{O}$ or $10 \%$ FBS-containing medium. The EDX results did not show significant difference in $\mathrm{Zn}$ and $\mathrm{O}$ elements between $\mathrm{ZnONP20}$ and $\mathrm{ZnONP90}$ when suspended in $\mathrm{dH}_{2} \mathrm{O}(86 \%-93 \%$ for $\mathrm{Zn}$ and $4 \%-7 \%$ for O) or $10 \%$ FBScontaining medium (86\%-91\% for $\mathrm{Zn}$ and 5\%-8\% for $\mathrm{O}$ ). Al was only detected in Al-ZnONP20, which consisted of
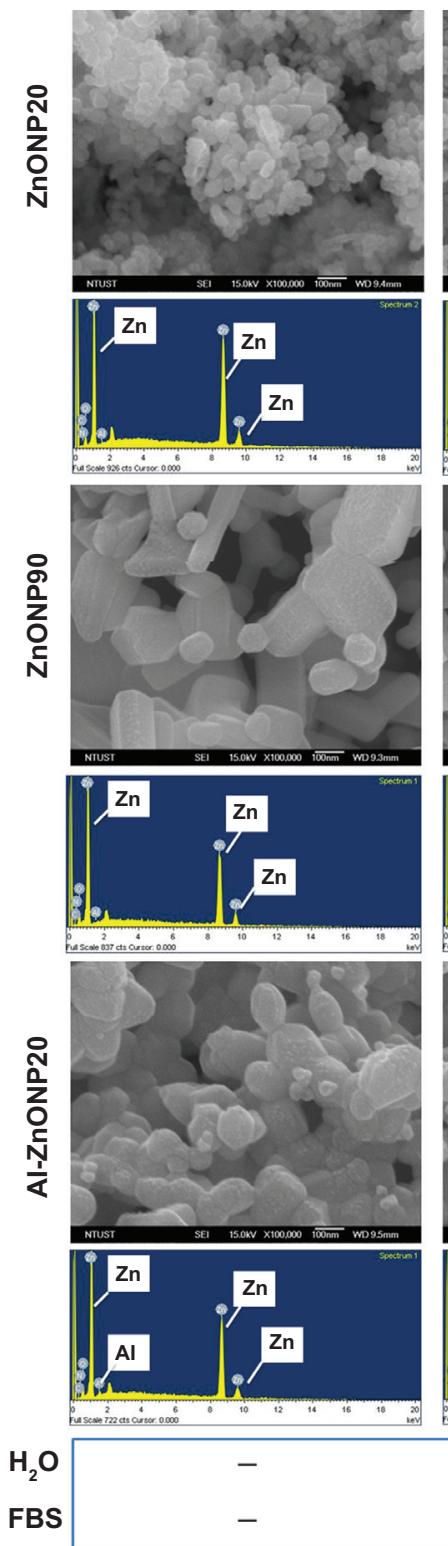
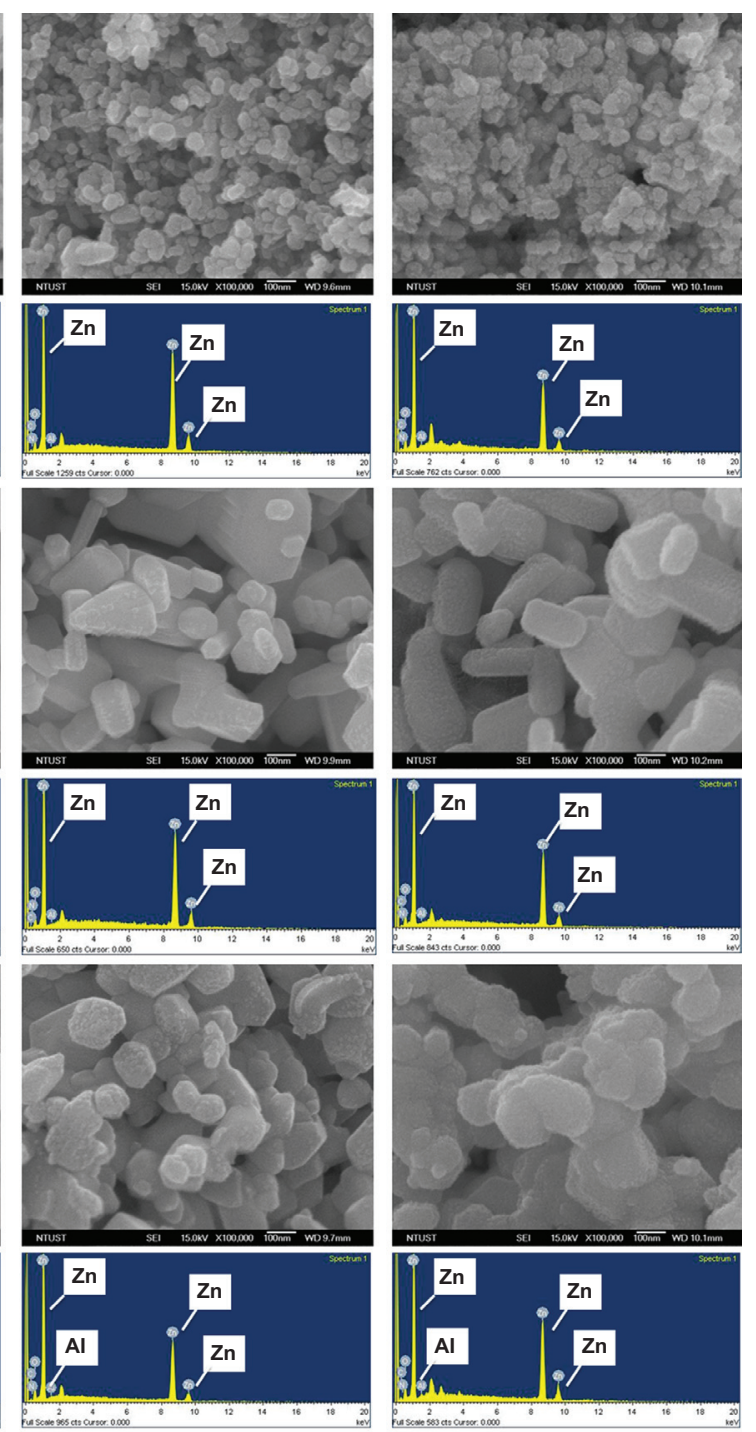

$+$

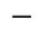

Figure I Scanning electron microscopy and energy-dispersive X-ray spectroscopy analyses of ZnONP20, ZnONP90, and Al-ZnONP20 with and without the addition of $\mathrm{dH}_{2} \mathrm{O}$ and a $10 \%$ FBS solution.

Abbreviations: ZnONP, zinc oxide nanoparticle; FBS, fetal bovine serum. 
$1 \% \mathrm{Al}, 85 \%-86 \% \mathrm{Zn}$, and $7 \% \mathrm{O}$ when suspended in $\mathrm{dH}_{2} \mathrm{O}$ or $10 \%$ FBS-containing medium.

To understand the physicochemical characteristics of the ZnONPs, we next investigated the hydrodynamic diameters of ZnONP20, ZnONP90, and Al-ZnONP20 at $20-500 \mu \mathrm{g} / \mathrm{mL}$ in $10 \%$ FBS-containing medium over 48 hours. The results of this analysis, as shown in Figure 2, indicate that the hydrodynamic diameters of the ZnONPs were 105 (at $20 \mu \mathrm{g} / \mathrm{mL}$ ) to 522 (at $500 \mu \mathrm{g} / \mathrm{mL}$ ) nm for ZnONP20, 98 (at $20 \mu \mathrm{g} / \mathrm{mL}$ ) to 486 (at $500 \mu \mathrm{g} / \mathrm{mL}$ ) nm for ZnONP90, and 53 (at $20 \mu \mathrm{g} / \mathrm{mL}$ ) to 967 (at $500 \mu \mathrm{g} / \mathrm{mL}$ ) nm for Al-ZnONP20 for 48 hours.
The hydrodynamic diameters of the ZnONPs increased over time, especially after 24-hour exposure $(P<0.05$, except for $\mathrm{ZnONP20}$ and $\mathrm{ZnONP90}$ at $20 \mu \mathrm{g} / \mathrm{mL}$ ). The zeta potentials of the ZnONPs were determined, as shown in Figure 2. The zeta potentials of ZnONP20, ZnONP90, and Al-ZnONP20 were between -17.56 and $-29.56 \mathrm{mV},-26.51$ and $-34.99 \mathrm{mV}$, and -21.62 and -29.25 , respectively, compared with $-18.17 \mathrm{mV}$ for $10 \%$ FBS (vehicle control, $0 \mu \mathrm{g} / \mathrm{mL}$ ). The absolute value of zeta-potential values increased over time during the 48-hour period $(P<0.05)$, except for $\mathrm{ZnONP} 20$ at 150 and $300 \mu \mathrm{g} / \mathrm{mL}$. A slight increase
ZnONP20
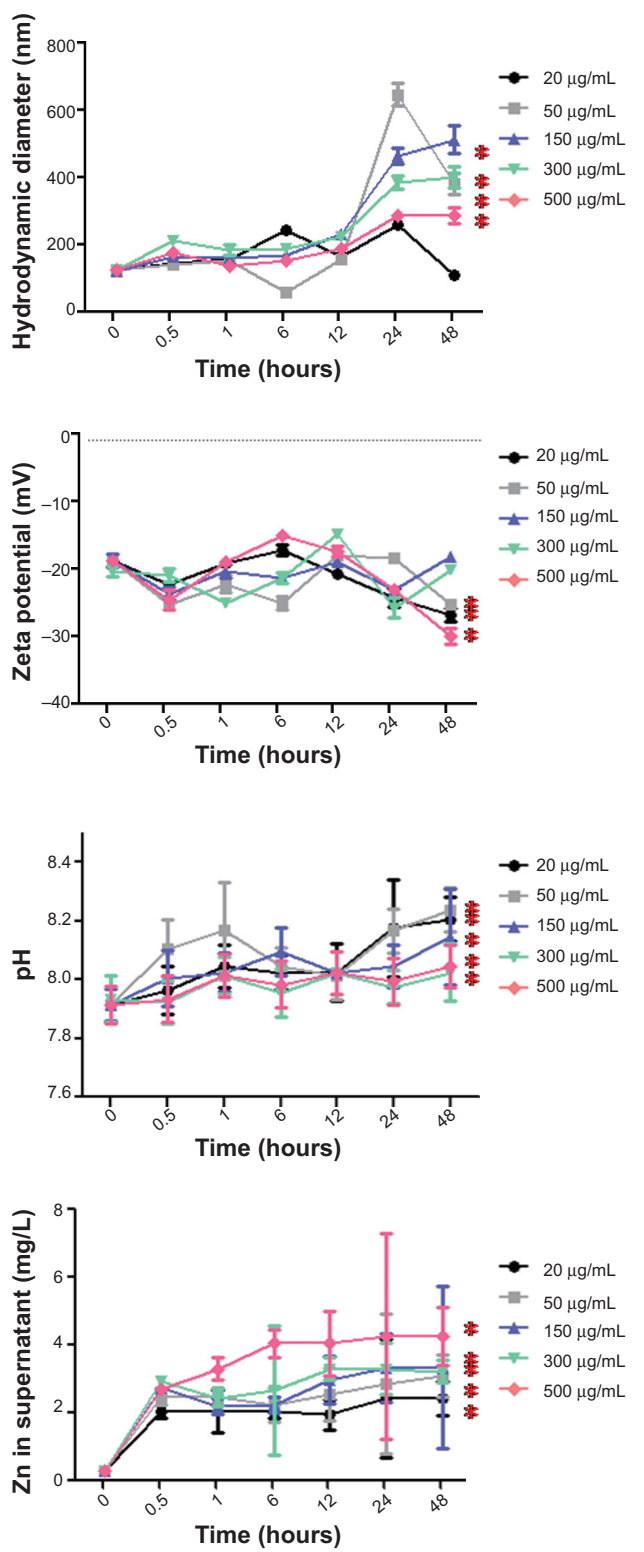

ZnONP90
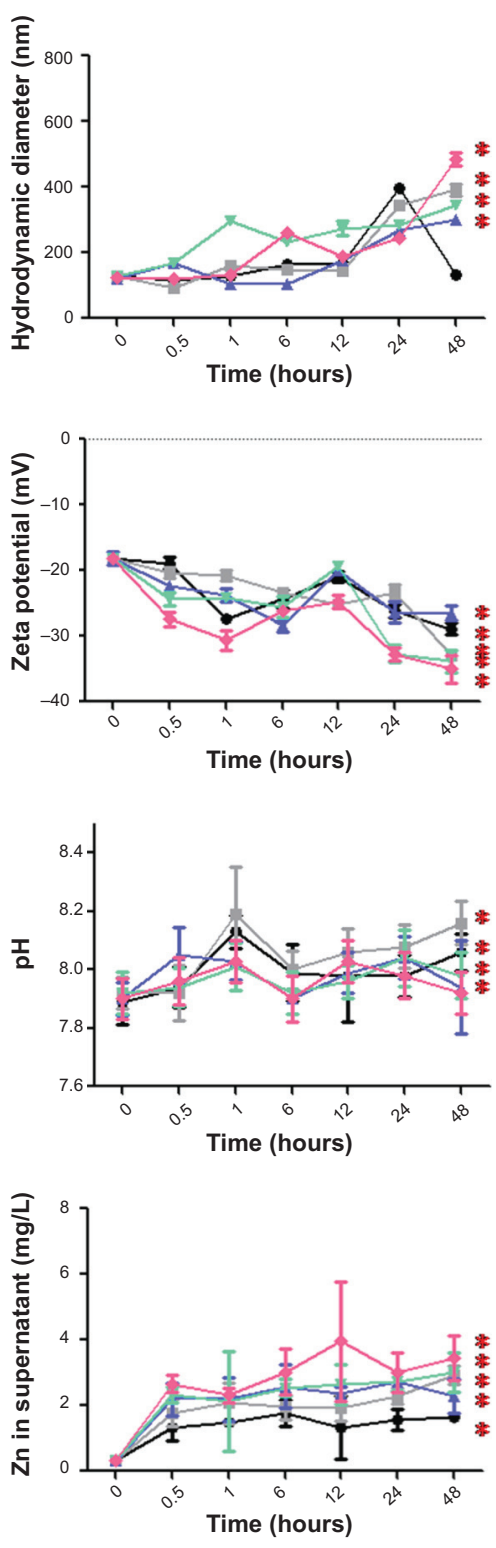

Al-ZnONP20
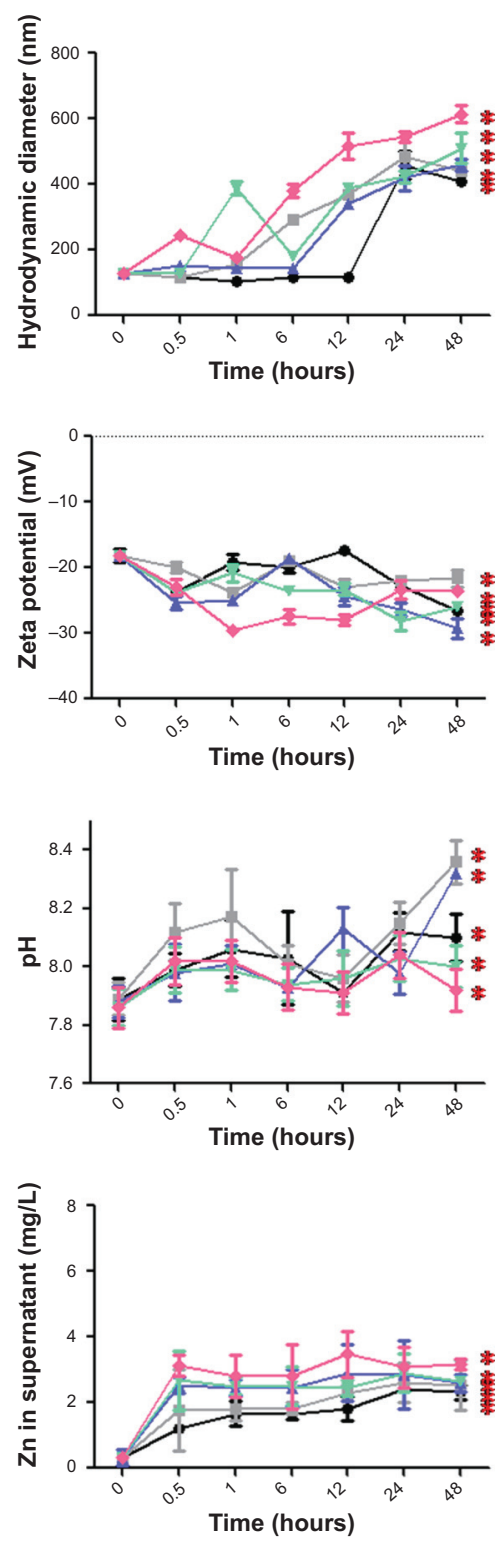

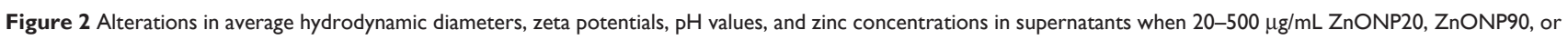
Al-ZnONP20 was suspended in 10\% FBS solution for 48 hours. Asterisks indicate significant differences compared with control at $P<0.05$.

Abbreviations: ZnONP, zinc oxide nanoparticle; FBS, fetal bovine serum. 
in $\mathrm{pH}$ values was observed when these particles were dispersed in the FBS solution (Figure 2, $P<0.05$ ), except for $\mathrm{ZnONP90}$ at $150 \mu \mathrm{g} / \mathrm{mL}$. We observed that the $\mathrm{pH}$ values were 8.03-8.24 for $\mathrm{ZnONP20,} \mathrm{7.92-8.16} \mathrm{for} \mathrm{ZnONP90,}$ and 7.92-8.32 for Al-ZnONP20. Zn leaching from these particles during the 48-hour period was also investigated. We observed that the concentrations of $\mathrm{Zn}$ that leached from ZnONP20 significantly increased over time $(P<0.05)$ and also demonstrated a significant dose-dependent response $(P<0.05)$, as shown in Figure 2. The concentrations of $\mathrm{Zn}$ that leached from $\mathrm{ZnONP90}$ and Al-ZnONP20 increased to a peak at 0.5 hour and remained stable throughout the remaining incubation time.

\section{Cell viability}

The xCELLigence system was used to investigate the realtime alteration in cell viability after exposure to $0-500 \mu \mathrm{g} / \mathrm{mL}$ ZnONP20,ZnONP90, or Al-ZnONP20 for 48 hours (Figure 3). We found that $\mathrm{ZnONP}$ exposure reduced cell viability significantly in a dose- and time-dependent manner compared with the controls $(P<0.05)$, especially when exposed to 150, 300, or $500 \mu \mathrm{g} / \mathrm{mL}$. Notably, $20 \mu \mathrm{g} / \mathrm{mL} Z \mathrm{ZnONP20}$, ZnONP90, or Al-ZnONP20 slightly decreased cell viability over time. Additionally, we observed that cell viability slightly increased at 2 hours postexposure in cells treated with any of the three particle types, followed by a continuous decrease in viability after 4 hours' exposure. The ranking of cell viability among these $\mathrm{ZnONPs}$ was Al-ZnONP20 > $\mathrm{ZnONP90}>\mathrm{ZnONP20}$ at $500 \mu \mathrm{g} / \mathrm{mL}$.

\section{Time-dependent associations between cell viability and physicochemistry of $\mathrm{ZnONPs}$}

Pearson's correlation coefficient was used to examine the correlations between cell viability and the physicochemical changes in the ZnONPs (hydrodynamic diameter, zeta potential, zinc ion release, and $\mathrm{pH}$ ) during a 48-hour exposure (Figure 3). Significant positive correlations were observed between cell viability and the zeta potentials of $\mathrm{ZnONP20}$ $(r=0.89, P<0.01)$ and Al-ZnONP20 $(r=0.80, P<0.05)$. Additionally, the alteration of cell viability by $\mathrm{ZnONP2} 20$ was negatively correlated with $\mathrm{pH}(r=-0.83, P<0.05)$. Statistically significant correlations were not observed between cell viability and hydrodynamic diameters or zinc ion release among these ZnONPs.

\section{Proteomic profiling of cell viability}

To understand the biological differences between a 2-hour (a slight increase in cell viability) and a 4-hour (a significant
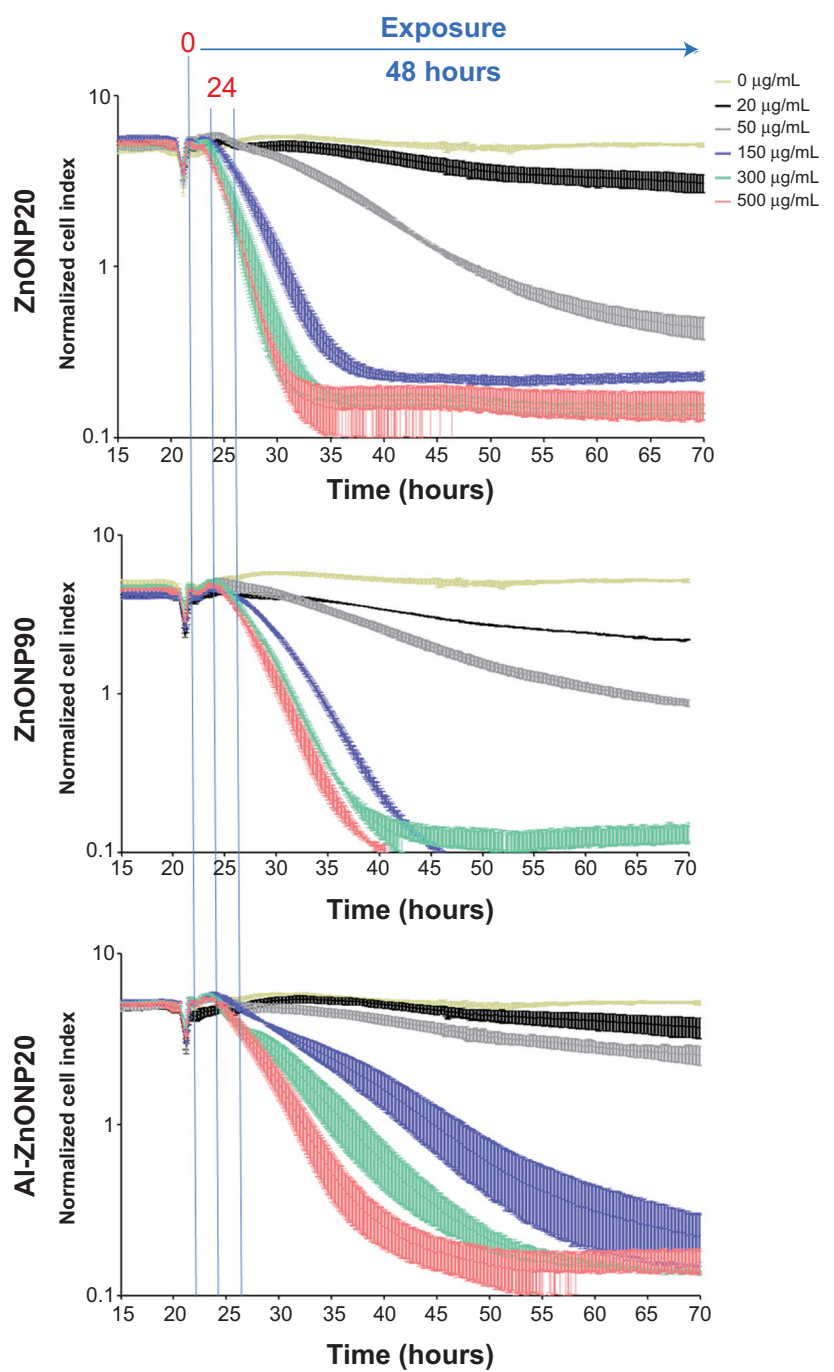

\begin{tabular}{lllll}
\hline Cell viability & $\begin{array}{l}\text { Hydrodynamic } \\
\text { diameter }\end{array}$ & $\begin{array}{l}\text { Zeta } \\
\text { potential }\end{array}$ & Zinc ion & pH \\
\hline ZnONP20 & 0.07 & $0.89 * *$ & -0.09 & $-0.83^{*}$ \\
ZnONP90 & -0.32 & 0.54 & -0.20 & -0.15 \\
Al-ZnONP20 & -0.56 & $0.80 *$ & 0.36 & -0.41 \\
\hline
\end{tabular}

Figure 3 Real-time alterations in cell viability after exposure to $0-500 \mu g / m L$ ZnONP20, ZnONP90, or Al-ZnONP20 for 48 hours.

Notes: The index of cell viability increased between 0 and 2 hours of exposure to the $\mathrm{ZnONPs}$, even at a relatively high mass concentration $(500 \mu \mathrm{g} / \mathrm{mL})$. Notably, cell death occurred after a 2-hour exposure, reducing the cell-viability index. Timedependent associations between cell viability and the physicochemistry of ZnONPs were determined using Pearson's correlation coefficient. Significant positive correlations were observed between cell viability andlzeta potentials of ZnONP20 $(r=0.89, P<0.01)$ and Al-ZnONP20 $(r=0.80, P<0.05)$. The alteration of cell viability by $\mathrm{ZnONP20}$ was negatively correlated with $\mathrm{pH}(r=-0.83, \mathrm{P}<0.05)$. Statistical associations were not observed between cell viability and hydrodynamic diameter or zinc ion (zinc ion concentration).

Abbreviation: ZnONP, zinc oxide nanoparticle.

decrease in cell viability) exposure to ZnONP20, ZnONP90, or Al-ZnONP20, we explored the proteomic profile of the proteins released from cells incubated with $20 \mu \mathrm{g} / \mathrm{mL} \mathrm{NPs}$, a concentration that produced a significant decrease in cell viability. In total, 87 proteins were identified in the control 
cells, whereas 87,70 , and 94 proteins were identified after a 2-hour exposure to ZnONP20, ZnONP90, and Al-ZnONP20, respectively. A total of 69,85 , and 96 proteins were identified after a 4-hour exposure to ZnONP20, ZnONP90, and $\mathrm{Al}-\mathrm{ZnONP20}$, respectively. These proteins are listed at $\mathrm{http} / / /$ www.dovepress.com/cr data/supplementary file 66651. pdf. To identify the proteins expressed after ZnONP20, $\mathrm{ZnONP90,} \mathrm{and} \mathrm{Al-ZnONP20} \mathrm{exposure,} \mathrm{the} \mathrm{overlaps} \mathrm{in} \mathrm{pro-}$ tein profiles between the control and ZnONP20, ZnONP90, and Al-ZnONP20 between 2 and 4 hours were examined
(Figure 4). There were eleven, three, and 18 proteins unique to cells exposed for 2 hours to ZnONP20, ZnONP90, and AlZnONP20, respectively (Table 2). There were eight, 12, and 20 proteins unique to cells exposed for 4 hours to $\mathrm{ZnONP20,}$ $\mathrm{ZnONP90,} \mathrm{and} \mathrm{Al-ZnONP20,} \mathrm{respectively} \mathrm{(Table} \mathrm{2).}$

MS-based functional pathway analyses were performed using the proteins unique to $\mathrm{ZnONP20,} \mathrm{ZnONP90,} \mathrm{and} \mathrm{Al-}$ ZnONP20 exposures to understand their biological context. PANTHER analysis was initially used to examine protein functions in biological processes (Figure 4). We observed that
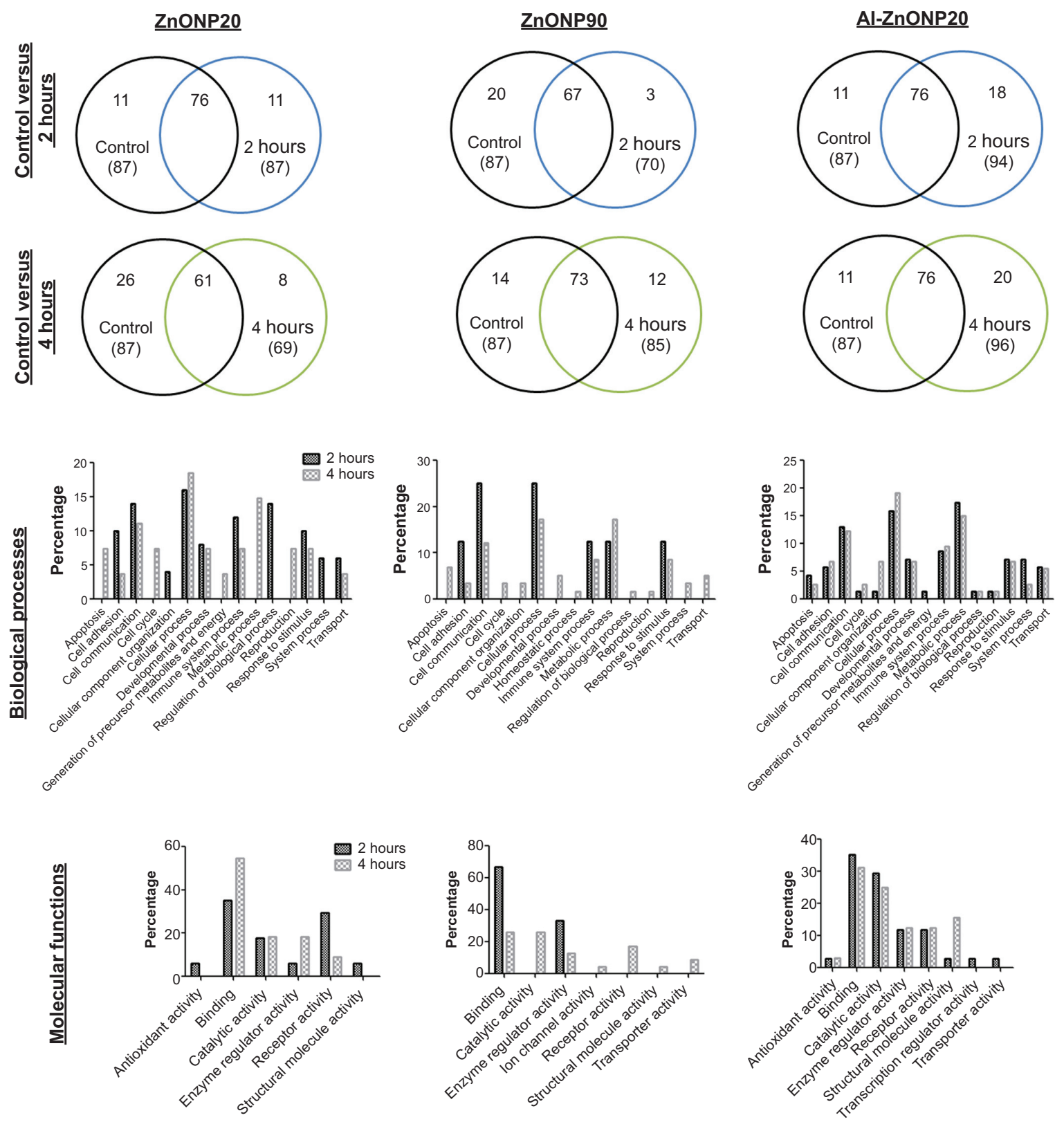

Figure 4 Venn diagrams showing the proteins common between or unique to ZnONP20, ZnONP90, and Al-ZnONP20 at 2 and 4 hours of exposure. Biological processes and molecular functions associated with 2-hour and 4-hour exposures to ZnONP20, ZnONP90, or Al-ZnONP20 were determined using PANTHER (Protein ANalysis THrough Evolutionary Relationships).

Abbreviation: ZnONP, zinc oxide nanoparticle. 
Table 2 Unique proteins expressed in response to ZnONP20, ZnONP90, and Al-ZnONP20 after 2-hour and 4-hour exposure

\begin{tabular}{|c|c|c|c|c|c|c|}
\hline Number & Name of protein & $\begin{array}{l}\text { Accession } \\
\text { number }\end{array}$ & $\begin{array}{l}\text { Mascot } \\
\text { score }\end{array}$ & $\begin{array}{l}\text { Calculated } \\
\text { MW (Da) }\end{array}$ & $\begin{array}{l}\text { Sequence } \\
\text { covered }(\%)\end{array}$ & $\begin{array}{l}\text { Calculated } \\
\text { PI }\end{array}$ \\
\hline \multicolumn{7}{|c|}{ ZnONP20 (2 hours) } \\
\hline I & Desmoglein-I & DSGI_HUMAN & 63 & 114,702 & 1.3 & 4.9 \\
\hline 2 & Keratin, type II cytoskeletal 78 & K2C78_HUMAN & 62 & 57,629 & 2.3 & 5.79 \\
\hline 3 & Junction plakoglobin & PLAK_HUMAN & 49 & 82,434 & 1.6 & 5.75 \\
\hline 4 & Exportin-I & XPOI_HUMAN & 49 & 124,447 & 0.9 & 5.71 \\
\hline 5 & ICOS ligand & ICOSL_HUMAN & 40 & 33,841 & 3.3 & 5.15 \\
\hline 6 & Tudor domain-containing protein 6 & TDRD6_HUMAN & 39 & 239,845 & 0.3 & 5.14 \\
\hline 7 & Serine/threonine-protein kinase $\mathrm{HI}$ & KPSHI_HUMAN & 34 & 48,347 & 2.8 & 9.82 \\
\hline 8 & Neutral $\alpha$-glucosidase $C$ & GANC_HUMAN & 33 & 104,839 & 0.8 & 5.82 \\
\hline 9 & Peroxiredoxin-2 & PRDX2_HUMAN & 32 & 22,049 & 8.6 & 5.66 \\
\hline 10 & Fibromodulin & FMOD_HUMAN & 31 & 43,494 & 2.9 & 5.66 \\
\hline II & Cadherin-13 & CADI3_HUMAN & 31 & 78,694 & 1.7 & 4.8 \\
\hline \multicolumn{7}{|c|}{ ZnONP20 (4 hours) } \\
\hline 1 & Keratin, type II cytoskeletal 6B & K2C6B_HUMAN & 749 & 60,315 & 20.6 & 8.09 \\
\hline 2 & Keratin, type II cytoskeletal Ib & K2CIB_HUMAN & 446 & 62,149 & 7.4 & 5.73 \\
\hline 3 & Desmoglein-I & DSGI_HUMAN & 143 & 114,702 & 3.9 & 4.9 \\
\hline 4 & Tudor domain-containing protein 6 & TDRD6_HUMAN & 44 & 239,845 & 0.3 & 5.14 \\
\hline 5 & Keratin, type II cytoskeletal 78 & K2C78_HUMAN & 37 & 57,629 & 2.3 & 5.79 \\
\hline 6 & Afamin & AFAM_HUMAN & 36 & 70,963 & 1.2 & 5.64 \\
\hline 7 & Heparin cofactor 2 & HEP2_HUMAN & 35 & 57,205 & 3.6 & 6.41 \\
\hline 8 & Kininogen-I & KNGI_HUMAN & 32 & 72,996 & $\mathrm{I} .4$ & 6.34 \\
\hline \multicolumn{7}{|c|}{ ZnONP90 ( 2 hours) } \\
\hline 1 & Keratin, type II cytoskeletal 6B & K2C6B_HUMAN & 1,220 & 60,315 & 37.1 & 8.09 \\
\hline 2 & Keratin, type II cytoskeletal 78 & K2C78_HUMAN & 68 & 57,629 & 2.3 & 5.79 \\
\hline 3 & Desmoglein-I & DSGI_HUMAN & 63 & 114,702 & 1.3 & 4.9 \\
\hline \multicolumn{7}{|c|}{ ZnONP90 (4 hours) } \\
\hline I & Keratin, type II cytoskeletal 6B & K2C6B_HUMAN & 749 & 60,315 & 20.6 & 8.09 \\
\hline 2 & Keratin, type II cytoskeletal Ib & K2CIB_HUMAN & 446 & 62,149 & 7.4 & 5.73 \\
\hline 3 & Desmoglein-I & DSGI_HUMAN & 143 & 114,702 & 3.9 & 4.9 \\
\hline 4 & Filaggrin-2 & FILA2_HUMAN & 93 & 249,296 & I & 8.45 \\
\hline 5 & Prolactin-inducible protein & PIP_HUMAN & 78 & 16,847 & 11 & 8.26 \\
\hline 6 & $\begin{array}{l}\text { Testis-specific Y-encoded-like } \\
\text { protein } 2\end{array}$ & TSYL2_HUMAN & 62 & 79,615 & I & 4.45 \\
\hline 7 & Complement factor I & CFAI_HUMAN & 61 & 68,102 & 2.2 & 7.72 \\
\hline 8 & ICOS ligand & ICOSL_HUMAN & 40 & 33,841 & 3.3 & 5.15 \\
\hline 9 & Cathepsin Z & CATZ_HUMAN & 49 & 34,530 & 3.3 & 6.7 \\
\hline 10 & $\begin{array}{l}\text { Protein kinase domain-containing } \\
\text { protein, cytoplasmic }\end{array}$ & PKDCC_HUMAN & 44 & 54,953 & 1.4 & 8.76 \\
\hline 11 & Complement component $\mathrm{C} 7$ & CO7_HUMAN & 37 & 96,650 & 0.9 & 6.09 \\
\hline 12 & $\begin{array}{l}\text { Phosphatidylcholine-sterol } \\
\text { acyltransferase }\end{array}$ & LCAT_HUMAN & 35 & 49,888 & 2.5 & 5.71 \\
\hline \multicolumn{7}{|c|}{ Al-ZnONP20 (2 hours) } \\
\hline I & Keratin, type II cytoskeletal 6B & K2C6B_HUMAN & 749 & 60,315 & 20.6 & 8.09 \\
\hline 2 & Keratin, type II cytoskeletal Ib & K2CIB_HUMAN & 446 & 62,149 & 7.4 & 5.73 \\
\hline 3 & Desmoglein-I & DSGI_HUMAN & 143 & $1 \mid 4,702$ & 3.9 & 4.9 \\
\hline 4 & Cartilage oligomeric matrix protein & COMP_HUMAN & $14 \mid$ & 85,431 & 4.4 & 4.36 \\
\hline 5 & Reticulocalbin-3 & RCN3_HUMAN & 125 & 37,470 & 8.2 & 4.74 \\
\hline 6 & Junction plakoglobin & PLAK_HUMAN & 105 & 82,434 & 5.9 & 5.75 \\
\hline 7 & Prolactin-inducible protein & PIP_HUMAN & 78 & 16,847 & 11 & 8.26 \\
\hline
\end{tabular}


Table 2 (Continued)

\begin{tabular}{|c|c|c|c|c|c|c|}
\hline Number & Name of protein & $\begin{array}{l}\text { Accession } \\
\text { number }\end{array}$ & $\begin{array}{l}\text { Mascot } \\
\text { score }\end{array}$ & $\begin{array}{l}\text { Calculated } \\
\text { MW (Da) }\end{array}$ & $\begin{array}{l}\text { Sequence } \\
\text { covered (\%) }\end{array}$ & $\begin{array}{l}\text { Calculated } \\
\text { pl }\end{array}$ \\
\hline 8 & Cathepsin Z & CATZ_HUMAN & 62 & 34,530 & 3.3 & 6.7 \\
\hline 9 & Fibromodulin & FMOD_HUMAN & 47 & 43,494 & 2.9 & 5.66 \\
\hline 10 & Periostin & POSTN_HUMAN & 41 & 93,883 & 2.4 & 7.27 \\
\hline II & Peroxiredoxin-2 & PRDX2_HUMAN & 43 & 22,049 & 8.6 & 5.66 \\
\hline 12 & Tubulin $\beta-2 A$ chain & TBB2A_HUMAN & 36 & 50,274 & 3.1 & 4.78 \\
\hline 13 & Keratinocyte proline-rich protein & KPRP_HUMAN & 35 & 67,172 & 3.6 & 8.72 \\
\hline 14 & Vitamin K-dependent protein S & PROS_HUMAN & 32 & 77,127 & 1.2 & 5.48 \\
\hline 15 & Kininogen-I & KNGI_HUMAN & 35 & 72,996 & 1.4 & 6.34 \\
\hline 16 & Syntaxin-19 & STXI9_HUMAN & 31 & 34,759 & 4.4 & 7.05 \\
\hline 17 & Ceruloplasmin & CERU_HUMAN & 30 & 122,983 & 0.9 & 5.44 \\
\hline 18 & Cyclin-G-associated kinase & GAK_HUMAN & 30 & 144,583 & 0.5 & 5.49 \\
\hline \multicolumn{7}{|c|}{ Al-ZnONP20 (4 hours) } \\
\hline I & Keratin, type II cytoskeletal 7 & K2C7_HUMAN & 1,749 & $5 I, 4 I I$ & 6.2 & 5.4 \\
\hline 2 & Keratin, type II cytoskeletal 6C & K2C6C_HUMAN & 1,335 & 60,273 & 38.7 & 8.09 \\
\hline 3 & Keratin, type II cytoskeletal 6B & K2C6B_HUMAN & 1,220 & 60,315 & 37.1 & 8.09 \\
\hline 4 & Desmoglein-I & DSGI_HUMAN & 236 & 114,702 & 2.9 & 4.9 \\
\hline 5 & Junction plakoglobin & PLAK_HUMAN & 164 & 82,434 & 9.9 & 5.75 \\
\hline 6 & Filaggrin-2 & FILA2_HUMAN & 93 & 249,296 & 1 & 8.45 \\
\hline 7 & Prolactin-inducible protein & PIP_HUMAN & 78 & 16,847 & II & 8.26 \\
\hline 8 & Keratin, type II cytoskeletal 78 & K2C78_HUMAN & 68 & 57,629 & 2.3 & 5.79 \\
\hline 9 & Desmocollin-I & DSCI_HUMAN & 61 & 101,406 & 1.6 & 5.25 \\
\hline 10 & Plakophilin-I & PKPI_HUMAN & 58 & 84,119 & 2 & 9.29 \\
\hline II & Microfibrillar-associated protein 5 & MFAP5_HUMAN & 54 & 20,055 & 6.4 & 5.64 \\
\hline 12 & Tudor domain-containing protein 6 & TDRD6_HUMAN & 39 & 239,845 & 0.3 & 5.14 \\
\hline 13 & Cadherin-13 & CADI3_HUMAN & 46 & 78,694 & 1.7 & 4.8 \\
\hline 14 & Peroxiredoxin-2 & PRDX2_HUMAN & 32 & 22,049 & 8.6 & 5.66 \\
\hline 15 & $\begin{array}{l}\text { Phosphatidylcholine-sterol } \\
\text { acyltransferase }\end{array}$ & LCAT_HUMAN & 36 & 49,888 & 2.5 & 5.71 \\
\hline 16 & Calmodulin-like protein 5 & CALL5_HUMAN & 34 & 15,883 & 15.8 & 4.34 \\
\hline 17 & Glucose-6-phosphate isomerase & G6PI_HUMAN & 33 & 63,335 & 2.7 & 8.43 \\
\hline 18 & $\begin{array}{l}\text { Heparan-sulfate 6-O- } \\
\text { sulfotransferase I }\end{array}$ & H6STI_HUMAN & 32 & 48,879 & 1.7 & 9.04 \\
\hline 19 & Caspase-14 & CASPE_HUMAN & 31 & 27,947 & 3.3 & 5.44 \\
\hline 20 & Cyclin-G-associated kinase & GAK_HUMAN & 30 & 144,583 & 0.5 & 5.49 \\
\hline
\end{tabular}

Abbreviations: ZnONP, zinc oxide nanoparticle; MW, molecular weight; pl, isoelectric point.

only proteins involved in cellular component organization (4\% for ZnONP20), the generation of precursor metabolites and energy (1.4\% for Al-ZnONP20), and system processes (6\% for ZnONP20) were present after a 2-hour exposure, whereas only proteins involved in apoptosis $(7.4 \%$ for ZnONP20 exposure and 6.9\% for ZnONP90 exposure), the cell cycle (7.4\% for ZnONP20 and 3.4\% for ZnONP90), cellular component organization (3.4\% for ZnONP90), developmental processes (5.2\% for ZnONP90), homeostatic processes (1.7\% for $\mathrm{ZnONP90),} \mathrm{the} \mathrm{regulation} \mathrm{of} \mathrm{biologi-}$ cal processes (1.7\% for ZnONP90), reproduction (1.7\% for ZnONP90), system processes (3.4\% for ZnONP90), and transport (5.2\% for ZnONP90) were present after a 4-hour exposure.

The molecular functions of these proteins unique to ZnONP20, ZnONP90, and Al-ZnONP20 exposure were also determined (Figure 4). We observed that only antioxidant activity (5.9\% for ZnONP20), structural molecule activity ( $5.9 \%$ for $\mathrm{ZnONP} 20$ ), transcription-regulator activity ( $2.9 \%$ for Al-ZnONP20), and transporter activity (2.9\% for Al-ZnONP20) were present after a 2-hour exposure. Notably, catalytic activity (26.1\%), ion-channel activity (4.3), receptor activity (17.4), structural molecule activity (4.3\%), and transporter activity (8.7) were only observed after a 4-hour exposure to ZnONP90. 


\section{Proteomic profiling of size and surface- chemistry effects on cell viability}

To understand the effects of particle size on cell viability, MS-based functional pathway analyses were performed on the proteins unique to $\mathrm{ZnONP20}$ ( 87 proteins for 2 hours and 69 proteins for 4 hours) and ZnONP90 (70 proteins for 2 hours and 85 proteins for 4 hours) exposure to understand their biological context. PANTHER analysis was also used to determine protein functions in cellular pathways (Figure 5). We observed that proteins involved in the blood-coagulation cascade (14.3\%), the cadherin signaling pathway (14.3\%), the circadian clock system (14.3\%), the gonadotropin-releasing hormone-receptor pathway (14.3\%), inflammation mediated by chemokine and cytokine signaling (14.3\%), the p53 pathway (14.3\%), and the Wnt signaling pathway (14.3\%) were expressed in response to a 2 -hour exposure to $\mathrm{ZnONP}$. The blood-coagulation cascade (33.3\%), the gonadotropin releasing hormone receptor pathway (33.3\%) and the TGF $\beta$ signaling pathway (33.3\%) were present after a 2-hour exposure to $\mathrm{ZnONP90.} \mathrm{A} \mathrm{4-hour} \mathrm{exposure} \mathrm{to} \mathrm{ZnONP20} \mathrm{activated} \mathrm{the}$ apoptosis signaling pathway (25\%) and blood-coagulation cascade $(75 \%)$, whereas a 4-hour ZnONP90 exposure induced proteins active in glycolysis (25\%), Huntington's disease (25\%), the integrin signaling pathway $(25 \%)$, and the p53 pathway $(25 \%)$.

We next investigated the effects of particle-surface characteristics on cell viability (Figure 5). MS-based functional pathway analyses were performed on the proteins unique to ZnONP20 (87 proteins at 2 hours and 69 proteins at 4 hours) and Al-ZnONP20 (94 proteins at 2 hours and 96 proteins at 4 hours) exposure to understand their biological context. We observed that the proteins involved in the bloodcoagulation cascade (40\%), the cadherin signaling pathway (20\%), Huntington's disease (20\%), and the Wnt signaling pathway (20\%) were present 2 hours after ZnONP20 exposure, whereas the proteins involved in the blood-coagulation cascade $(20 \%)$, cytoskeletal regulation by Rho guanosine triphosphatase (10\%), Huntington's disease (10\%), the insulin/IGF pathway-mitogen-activated protein kinase kinase/MAP kinase cascade (10\%), the insulin/IGF pathway-protein kinase B signaling cascade/integrin signaling pathway (10\%), the ionotropic glutamate-receptor pathway/ muscarinic acetylcholine receptor 2 and 4 signaling pathway $(10 \%)$, and the nicotinic acetylcholine receptor signaling pathway $(10 \%)$ were found after a 2-hour Al-ZnONP20 exposure. Only proteins involved in the blood-coagulation

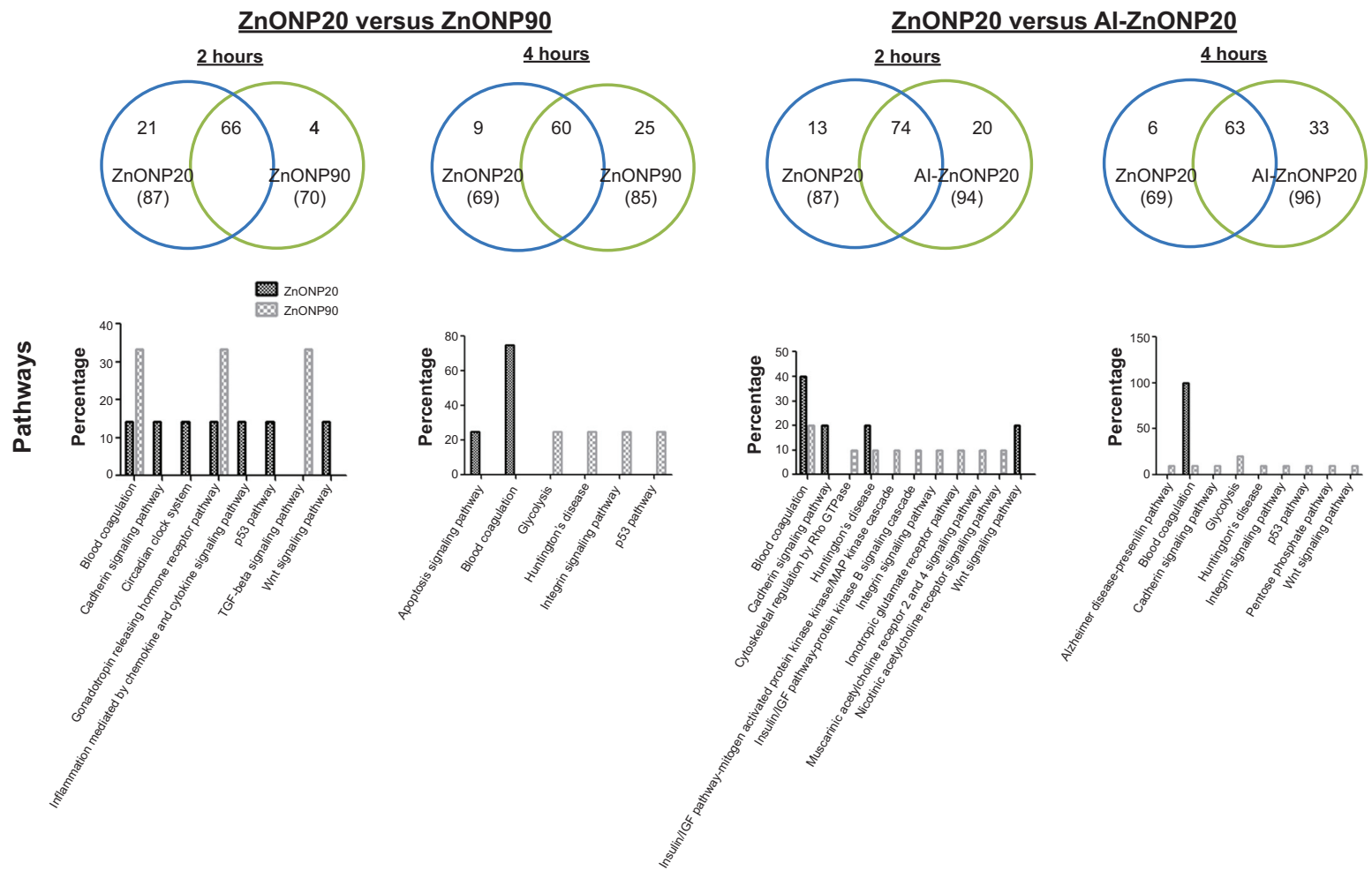

Figure 5 Venn diagrams showing the proteins common between or unique to ZnONP20 and ZnONP90 (size effect) and ZnONP20 and Al-ZnONP20 (surface effect) at 2 hours and 4 hours of exposure. Pathways associated with 2-hour and 4-hour exposure to ZnONP20 and ZnONP90 (size effect) and ZnONP20 and Al-ZnONP20 (surface effect) were determined using PANTHER (Protein ANalysis THrough Evolutionary Relationships).

Abbreviation: $\mathrm{ZnONP}$, zinc oxide nanoparticle. 
cascade $(100 \%)$ were identified after a 4-hour exposure to ZnONP20. Proteins involved in the Alzheimer's diseasepresenilin pathway $(10 \%)$, the blood-coagulation cascade $(10 \%)$, the cadherin signaling pathway $(10 \%)$, glycolysis (20\%), Huntington's disease (10\%), the integrin signaling pathway $(10 \%)$, the p53 pathway $(10 \%)$, the pentose-phosphate pathway (10\%), and the Wnt signaling pathway (10\%) were present after a 4-hour exposure to Al-ZnONP20.

\section{Discussion}

With regard to the toxicology of ZnONPs, smaller particles, which have a greater surface area per unit mass than do larger particles, may be associated with higher bioreactivity. Additionally, differences in the surface characteristics of particles may also play important roles in the regulation of cellular bioreactivity. ${ }^{23}$ For these reasons, the present study explored the feasibility of using proteomics to investigate cell viability in alveolar epithelial cells as a basis for the development of high-throughput screens and more focused assessments of the effects of size and surface characteristics of ZnONPs.

Physicochemical characterization in toxicological experiments is a key step in NP toxicological testing. Considering the significance in determining the biological outcomes of ZnONP exposure and how important modifications can create "safe-by-design" nanoproducts, we investigated the dosedependent and time-dependent nature of the physicochemistry of ZnONPs. In this study, two different sizes of ZnONPs (ZnONP20 and ZnONP90) were used to investigate size effects, and the similarly sized ZnONP20 and Al-ZnONP20, but having different electrical and electronic properties, were used to investigate surface effects. No significant change in morphology was observed among these ZnONPs when dispersed in water or FBS solution. Previous studies reported that serum proteins act as an excellent dispersant for ZnONPs in biological solutions, ${ }^{14,23}$ which is consistent with our finding that the addition of FBS dispersed $\mathrm{ZnONPs}$ well at various mass concentrations $(20-500 \mu \mathrm{g} / \mathrm{mL})$. However, dispersion in FBS-containing medium was reduced over time. We found reaggregation of ZnONPs occurred after 6 hours, especially at higher mass concentrations. Additionally, the hydrodynamic diameters of ZnONP20 and ZnONP90 partially overlapped, which may have contributed to the reaggregation of the particles over 48 hours. The zeta-potential values also slightly decreased over time. Taken together, these results suggest that serum proteins may be a good dispersant for $\mathrm{ZnONPs,}$ but the dispersive effects are only maintained for a short time, after which aggregation/agglomeration recurs. The use of other ZnONPs with distinct size distributions may be required in future studies. The stabilization of ZnONPs in serum primarily occurs through protein adsorption and the resulting net surface charge, as reported by Wells et al. ${ }^{16}$ The alterations in the zeta potentials of the ZnONPs may result from the change in $\mathrm{pH}$ over a 48-hour period, which is supported by the work of Shahmoradi et al. ${ }^{17}$ The ZnONPs leached $\mathrm{Zn}$ into the solution, and relatively stable $\mathrm{Zn}$ levels were maintained for 48 hours, which is similar to the findings of our previous study. ${ }^{23}$

Cell viability is a common indicator in toxicological testing; however, alterations in cell viability also relate to the cutoff time. To obtain a better understanding of doseand time-dependent changes in cell viability, the real-time viability of A549 cells after exposure to ZnONP20, ZnONP90, or Al-ZnONP20 was monitored. We observed that the index of cell viability increased between 0 and 2 hours of exposure to the $\mathrm{ZnONPs}$, even at a relatively high mass concentration $(500 \mu \mathrm{g} / \mathrm{mL})$. Notably, cell death occurred after a 2-hour exposure, reducing the cell-viability index. This finding suggests that a 2-hour exposure may be the longest that can be used for nanotoxicology testing of such particles as ZnONPs. To understand how NPs alter cellular bioreactivity before and after the 2-hour cutoff time point, protein profiling and the biological context of the identified proteins were determined. Proteins involved in apoptosis, the cell cycle, and reproduction were each present after exposure to $\mathrm{ZnONP20}$ or $\mathrm{ZnONP90}$ for 4 hours. Proteins involved in the generation of precursor metabolites and energy were characterized at 2 hours postexposure to Al-ZnONP20. Our findings were consistent with previous reports that $\mathrm{ZnONPs}$ induced cell death via apoptotic pathways ${ }^{12,26}$ and alterations in the cell cycle. ${ }^{27,28}$ The different biological processes activated in response to $\mathrm{ZnONP20,} \mathrm{ZnONP90,} \mathrm{and} \mathrm{especially}$ Al-ZnONP20 could have resulted from particle-size and surface differences.

To determine the effects of the size and surface characteristics of ZnONPs on biological processes, protein-profile comparisons between $\mathrm{ZnONP20}$ and $\mathrm{ZnONP90}$ and between ZnONP20 and Al-ZnONP20 after a 2-hour or 4-hour exposure were performed. We found that the proteins of the cadherin signaling pathway, the circadian clock system, inflammation mediated by chemokine and cytokine signaling, the p53 pathway, and the Wnt signaling pathway were present after a 2-hour exposure to ZnONP20. In contrast, proteins associated with the apoptosis signaling pathway and the blood-coagulation cascade were present after a 4-hour exposure. However, the TGF $\beta$ signaling pathway was only identified after a 2-hour exposure to $\mathrm{ZnONP90,} \mathrm{whereas}$ 
glycolysis, Huntington's disease, the integrin signaling pathway, and the p53 pathway were identified after a 4-hour exposure to ZnONP90. These findings suggest that smaller ZnONPs may have more acute toxic biological effects, such as activation of cell death, than do larger ZnONPs, but the results could also reflect the corresponding numbers of ZnONPs per unit mass. ${ }^{29}$ Additionally, the cells showed activation of distinct biological pathways in response to ZnONPs of different sizes. The proteins of the Wnt signaling pathway, for example, were only expressed after exposure to $\mathrm{ZnONP20}$, and the TGF $\beta$ signaling pathway was only identified after exposure to ZnONP90. The p53-pathway proteins were present at 2 hours of ZnONP20 and 4 hours of ZnONP90 treatment, suggesting that the p53 pathway could be the core mechanism responsible for zinc-based NP-induced cell death. ${ }^{26}$ We further showed that the WNT signaling pathway and the TGF $\beta$ signaling pathway regulated different cellular fates in cells treated with ZnONP20 and ZnONP90, respectively. The Wnt and TGF $\beta$ pathways are crucial mechanisms for controlling cell differentiation and cell fate. Cho et al indicated that expression of TGF $\beta$ was associated with $\mathrm{ZnONP}$ exposure. ${ }^{30}$

With regard to the differences in surface effects between ZnONP20 and Al-ZnONP20, our results demonstrated that the cadherin signaling pathway and the Wnt signaling pathway were active after a 2-hour ZnONP20 exposure and a 4-hour Al-ZnONP20 exposure. This result shows that cell fate and cell integration are important biological responses to smaller ZnONPs. Notably, the delayed biological effects could have resulted from the surface characteristics of the two ZnONPs. Therefore, an investigation of the correlations between the physicochemical parameters and cell death was conducted. Our results further showed that cytotoxicity might have been associated with zeta potential and $\mathrm{pH}$. It is known that Al dopants in $\mathrm{ZnO}$ can significantly modify the electronic properties of the material. $\mathrm{Xu}$ et al reported that $\mathrm{Al}-\mathrm{ZnONP}$ was more conductive than nondoped $\mathrm{ZnO}$ and that the electronic properties correlated with cytotoxicity. ${ }^{31}$ Furthermore, the higher positive charge could be more toxic to cells. ${ }^{5}$ The surface differences between ZnONP20 and Al-ZnONP20 were also related to the $\mathrm{pH}$, which is supported by work from Chusuei et al. ${ }^{32}$ Previous studies showed that $\mathrm{Zn}$ ion plays an important role in the regulation of $\mathrm{ZnONP}$ toxicity; ${ }^{30,33}$ however this association was not observed in our study. The difference may be due to the leached $\mathrm{Zn}$ ion reaching a plateau for 0.5 hour, following a stable $\mathrm{Zn}$ ion level over 48 hours. Real-time alteration in cell viability caused by different concentrations of $\mathrm{Zn}$ ion should be investigated in future work.

\section{Conclusion}

In conclusion, we have shown that the size and surface characteristics of ZnONPs play important roles in the regulation of cell viability, which was inferred from proteomic analyses. We also provide a better understanding of the biological effects of ZnONP exposure. Regarding the toxicity of surface properties, zeta potential and $\mathrm{pH}$ may be crucial characteristics for cell viability, which needs to be investigated in future work. Surface area is considered to be a determinant for nanotoxicity, ${ }^{34}$ which needs to be investigated in future work. Also, unisize isotopic ZnONPs may be used to clarify the size effects and surface effects on cell viability. Our findings have significant implications for discovering the biological responses responsible for the effects of $\mathrm{ZnONPs}$ at the molecular level, and continued work is required to more thoroughly elucidate the mechanisms involved.

\section{Acknowledgments}

The authors wish to thank Miss Yi-Syuan Lin for technical assistance during this project. This study was funded by the Institute of Labor, Occupational Safety and Health, Ministry of Labor, Taiwan (IOSH102-M321) and the Taipei Medical University and Shuang Ho Hospital (TMU101-AE1-B58 and 102TMU-SHH-19).

\section{Author contributions}

All authors contributed substantially to the concept and design of the study, the drafting of the article, and the critical revision of the manuscript for important intellectual content. All authors have read and approved the final version of the manuscript for publication.

\section{Disclosure}

The authors report no conflicts of interest in this work.

\section{References}

1. Nel A, Xia T, Meng H, et al. Nanomaterial toxicity testing in the $21 \mathrm{st}$ century: use of a predictive toxicological approach and high-throughput screening. Acc Chem Res. 2013;46(3):607-621.

2. Okoturo-Evans O, Dybowska A, Valsami-Jones E, et al. Elucidation of toxicity pathways in lung epithelial cells induced by silicon dioxide nanoparticles. PLoS One. 2013;8(9):e72363.

3. Aydin Sevinc B, Hanley L. Antibacterial activity of dental composites containing zinc oxide nanoparticles. J Biomed Mater Res B Appl Biomater. 2010;94(1):22-31.

4. Rasmussen JW, Martinez E, Louka P, Wingett DG. Zinc oxide nanoparticles for selective destruction of tumor cells and potential for drug delivery applications. Expert Opin Drug Deliv. 2010;7(9):1063-1077.

5. Akhtar MJ, Ahamed M, Kumar S, Khan MM, Ahmad J, Alrokayan SA. Zinc oxide nanoparticles selectively induce apoptosis in human cancer cells through reactive oxygen species. Int J Nanomedicine. 2012;7: 845-857. 
6. Sun J, Wang S, Zhao D, Hun FH, Weng L, Liu H. Cytotoxicity, permeability, and inflammation of metal oxide nanoparticles in human cardiac microvascular endothelial cells: cytotoxicity, permeability, and inflammation of metal oxide nanoparticles. Cell Biol Toxicol. 2011; 27(5):333-342.

7. Hanley C, Thurber A, Hanna C, Punnoose A, Zhang J, Wingett DG. The influences of cell type and $\mathrm{ZnO}$ nanoparticle size on immune cell cytotoxicity and cytokine induction. Nanoscale Res Lett. 2009;4(12): 1409-1420.

8. Frohlich E. The role of surface charge in cellular uptake and cytotoxicity of medical nanoparticles. Int J Nanomedicine. 2012;7:5577-5591.

9. Wilson WW, Wade MM, Holman SC, Champlin FR. Status of methods for assessing bacterial cell surface charge properties based on zeta potential measurements. J Microbiol Methods. 2001;43(3):153-164.

10. Suchea S, Christoulakis M, Katsarakis N, Kitsopoulos T. Comparative study of zinc oxide and aluminum doped zinc oxide transparent thin films grown by direct current magnetron sputtering. Thin Solid Films. 2007;515(16):6562-6566.

11. Wang X, Ou D, Yin J, Wu G, Wang J. Proteomic analysis reveals altered expression of proteins related to glutathione metabolism and apoptosis in the small intestine of zinc oxide-supplemented piglets. Amino Acids. 2009;37(1):209-218.

12. Kao YY, Chen YC, Cheng TJ, Chiung YM, Liu PS. Zinc oxide nanoparticles interfere with zinc ion homeostasis to cause cytotoxicity. Toxicol Sci. 2012;125(2):462-472.

13. Buerki-Thurnherr T, Xiao L, Diener L, et al. In vitro mechanistic study towards a better understanding of $\mathrm{ZnO}$ nanoparticle toxicity. Nanotoxicology. 2013;7(4):402-416.

14. Cho WS, Duffin R, Poland CA, et al. Differential pro-inflammatory effects of metal oxide nanoparticles and their soluble ions in vitro and in vivo; zinc and copper nanoparticles, but not their ions, recruit eosinophils to the lungs. Nanotoxicology. 2012;6(1):22-35.

15. Fang T, Watson JL, Goodman J, et al. Does doping with aluminum alter the effects of $\mathrm{ZnO}$ nanoparticles on the metabolism of soil pseudomonads? Microbiol Res. 2013;168(2):91-98.

16. Wells MA, Abid A, Kennedy IM, Barakat AI. Serum proteins prevent aggregation of $\mathrm{Fe}_{2} \mathrm{O}_{3}$ and $\mathrm{ZnO}$ nanoparticles. Nanotoxicology. 2012;6: 837-846.

17. Shahmoradi B, Soga K, Ananda S, Somashekar R, Byrappa K. Modification of neodymium-doped $\mathrm{ZnO}$ hybrid nanoparticles under mild hydrothermal conditions. Nanoscale. 2010;2(7):1160-1164.

18. Benninghoff A. Toxicoproteomics - the next step in the evolution of environmental biomarkers. Toxicol Sci. 2007;95(1):1-4.

19. Su CL, Chen TT, Chang CC, et al. Comparative proteomics of inhaled silver nanoparticles in healthy and allergen provoked mice. Int J Nanomedicine. 2013;8:2783-2799.
20. Jang KS, Sweredoski MJ, Graham RL, Hess S, Clemons WM Jr. Comprehensive proteomic profiling of outer membrane vesicles from Campylobacter jejuni. J Proteomics. 2013;98:90-98.

21. Srivastava R, Ray S, Vaibhav V, et al. Serum profiling of leptospirosis patients to investigate proteomic alterations. J Proteomics. 2012;76 Spec No:56-68.

22. Chuang HC, Jones T, BéruBé K. Combustion particles emitted during church services: implications for human respiratory health. Environ Int. 2012;40:137-142.

23. Chuang HC, Juan HT, Chang CN, et al. Cardiopulmonary toxicity of pulmonary exposure to occupationally relevant zinc oxide nanoparticles. Nanotoxicology. 2014;8(6):593-604.

24. Koop A, Sellami N, Adam-Klages S, et al. Down-regulation of the cancer/testis antigen 45 (CT45) is associated with altered tumor cell morphology, adhesion and migration. Cell Commun Signal. 2013; 11(1):41.

25. Chen TT, Chuang KJ, Chiang LL, et al. Characterization of the interactions between protein and carbon black. J Hazard Mater. 2014; 264:127-135.

26. Meyer K, Rajanahalli P, Ahamed M, Rowe JJ, Hong Y. ZnO nanoparticles induce apoptosis in human dermal fibroblasts via p53 and p38 pathways. Toxicol In Vitro. 2011;25(8):1721-1726.

27. Kumari M, Khan SS, Pakrashi S, Mukherjee A, Chandrasekaran N. Cytogenetic and genotoxic effects of zinc oxide nanoparticles on root cells of Allium cepa. J Hazard Mater. 2011;190(1-3):613-621.

28. Kocbek P, Teskac K, Kreft ME, Kristl J. Toxicological aspects of long-term treatment of keratinocytes with $\mathrm{ZnO}$ and $\mathrm{TiO}_{2}$ nanoparticles. Small. 2010;6(17):1908-1917.

29. Oberdörster G, Maynard A, Donaldson K, et al. Principles for characterizing the potential human health effects from exposure to nanomaterials: elements of a screening strategy. Part Fibre Toxicol. 2005;2:8.

30. Cho WS, Duffin R, Howie SE, et al. Progressive severe lung injury by zinc oxide nanoparticles; the role of $\mathrm{Zn}^{2}+$ dissolution inside lysosomes. Part Fibre Toxicol. 2011;8:27.

31. Xu M, Fujita D, Kajiwara S, et al. Contribution of physicochemical characteristics of nano-oxides to cytotoxicity. Biomaterials. 2010; 31(31):8022-8031.

32. Chusuei CC, Wu CH, Mallavarapu S, et al. Cytotoxicity in the age of nano: the role of fourth period transition metal oxide nanoparticle physicochemical properties. Chem Biol Interact. 2013;206(2):319-326.

33. Wallenborn JG, Evansky P, Shannahan JH, et al. Subchronic inhalation of zinc sulfate induces cardiac changes in healthy rats. Toxicol Appl Pharmacol. 2008;232(1):69-77.

34. Ho M, Wu KY, Chein HM, Chen LC, Cheng TJ. Pulmonary toxicity of inhaled nanoscale and fine zinc oxide particles: mass and surface area as an exposure metric. Inhal Toxicol. 2011;23(14):947-956.
International Journal of Nanomedicine

\section{Publish your work in this journal}

The International Journal of Nanomedicine is an international, peerreviewed journal focusing on the application of nanotechnology in diagnostics, therapeutics, and drug delivery systems throughout the biomedical field. This journal is indexed on PubMed Central, MedLine, CAS, SciSearch $\AA$, Current Contents ${ }^{\circledR} /$ Clinical Medicine,

\section{Dovepress}

Journal Citation Reports/Science Edition, EMBase, Scopus and the Elsevier Bibliographic databases. The manuscript management system is completely online and includes a very quick and fair peer-review system, which is all easy to use. Visit http://www.dovepress.com/ testimonials.php to read real quotes from published authors. 